\title{
The Ageing Scenario of the Italian Population
}

\author{
Giuseppina Sacco \\ Pietro Sacco
}

University of Bari,

Department of Scienze Economiche e metodi matematici, Bari

I belong to the emerging class, the old people one, that is more and more increasing and is supposed to exploit what we still have of humanity. The world is polarizing: the elderly on one side and nurses on the opposite one.

(Carlo Gragnani)

A dying old person is a library on fire.

(African proverb)

doi: 10.19044/esj.2016.v12n35p1 URL:http://dx.doi.org/10.19044/esj.2016.v12n35p1

\section{Abstract}

Population ageing is the most remarkable phenomenon that characterized the structure of the Italian population in the $20^{\text {th }}$ century and will mark the 21st century in the same way. "Population ageing" is the increase of incidence of elderly within the total population. In highly developed countries, this phenomenon has been recording higher and higher values in in the past 50 years ; this is particularly so in the case of Italy. Even while that may be seen as "a triumph of the development and one of the greatest successes of humanity", the phenomenon arouses a number of concerns because it involves far-reaching consequences for all social factors, thus signalling a wide range of challenges to be faced. These challenges will concern the economic and production system but, at the same time, they might also offer remarkable opportunities stemming from a new balance between generations. In this essay we will focus on the ageing phenomenon in Italy during the period between the 1951 census and 1st January 2015.

The indeces that are usually created to measure the ageing rate of population are the old-age index defined as the ratio between the over-65 and the young population, and the ageing index defined as the ratio between the over-65s and the total population. In this work we use the second indicator, which is considered adequate to determine whether a population can be described as "old".

Keywords: Ageing, Italy, increase 


\section{Evolution of the ageing rate of the Italian population}

The evolution of the ageing rate of the Italian population considered in this work was observed over two different periods of time: from the past to the present through the analysis of the "velocity" with which the phenomenon occurred in the period between the 1951 census and $1^{\text {st }}$ January 2015; from the past to the future by estimating how the ageing indeces would evolve if we study the trend observed in the past and by hypothesizing that the conditions that determined the evolution of the phenomenon observed in the past continue in the future as well.

As far as the measurement of the observed phenomenon time evolution is concerned, we firstly need to examine a space comparison, as this helps in understanding the present level of the "ageing" phenomenon in Italy. This is thus compared it with the indeces concerning the ageing population of some other developed countries until 2014 (see Chart 1).

Once it is determined that a population can be considered "old" if their ageing rate passes the $10 \%$ mark, from the chart analysis we can infer that all the examined countries have already reached a critical ageing level. Italy in particular, with an indicator equal to $22.0 \%$, is high among the countries considered and execeded only by Japan which as the highest level of population ageing in the world.

Chart 1 - Ageing indexes in some countries of the world

\begin{tabular}{|c|c|c|}
\hline Countries & $\begin{array}{c}\text { Population } \\
\text { (millions of inhabitants) }\end{array}$ & $A_{v}=\frac{P_{65-\omega}}{P_{0-\omega}} \cdot 100$ \\
\hline U.S.A. & 319 & 14.4 \\
Japan & 127 & 25.7 \\
Russian Federation & 144 & 13.2 \\
United Kingdom & 64 & 17.5 \\
France & 66 & 18.7 \\
Germany & 81 & 21.1 \\
Italy & 61 & 22.0 \\
\hline
\end{tabular}

Source: World Bank

\section{Ageing rate "velocity"}

In order to study the variation "velocity" that the ageing indeces demonstrated during the observation period, we calculated the variation rate, considered as an "average velocity”, through the following geometric growth model:

$$
A_{v, t}=A_{v, 0}(1+r)^{t}
$$

Where $A_{v, 0}$ and $A_{v, t}$ are the ageing indeces of the population in times 0 and $t$ while $r$ represents the yearly average variation of the ageing index from a year to the other one.

From the previous formula we infer: 


$$
r=\sqrt[t]{\frac{A_{v, t}}{A_{v, 0}}}-1
$$

In order to get a complete view of the ageing rate in our country, we calculated the ageing rates and the pertinent average velocity, for both sexes and for all Italian regions during the period between the $4^{\text {th }}$ November 1951census and $1^{\text {st }}$ January 2015.

Chart 2 shows the ageing indexes of the Italian population in total (MF) as well as for each Italian region, as well as the male (M) and female (F) composition, while Chart 3 shows the "velocity" $r$, that is the growth rate of the ageing level from 1951 to $1^{\text {st }}$ January 2015.

If we analyse the data of Chart 2, we realize that the ageing index of the Italian population altogether (MF) in 1951 was $8.2 \%$ while by $1^{\text {st }}$ January 2015 it had become $21.7 \%$. This is a remarkable increase that places Italy among the "oldest" countries in the world. In the same period, the ageing level of the male population (M) increased from $7.6 \%$ to $19.2 \%$ while that of the female group (F), which was $8.8 \%$ in 1951 , reached $24.1 \%$ in 2015 .

Chart 2 - Population ageing indeces of Italian regions

\begin{tabular}{|c|c|c|c|c|c|c|}
\hline \multirow{2}{*}{ Regions } & \multicolumn{2}{|c|}{$\mathrm{M}$} & \multicolumn{2}{|c|}{$\mathrm{F}$} & \multicolumn{2}{|c|}{ MF } \\
\hline & 1951 & 1.1.2015 & 1951 & 1.1 .2015 & 1951 & 1.1 .2015 \\
\hline Piemonte & 10.5 & 21.7 & 12.2 & 27.0 & 11.4 & 24.5 \\
\hline Valle d'Aosta & 8.7 & 20.0 & 9.5 & 24.9 & 9,1 & 22.5 \\
\hline Liguria & 10.0 & 24.5 & 11.3 & 31.1 & 10.6 & 28.0 \\
\hline Lombardia & 7.4 & 18.8 & 8.7 & 24.3 & 8.0 & 21.6 \\
\hline Trentino A.A. & 7.4 & 17.4 & 8.9 & 22.2 & 8.2 & 19.8 \\
\hline Veneto & 7.0 & 19.0 & 8.3 & 24.2 & 7.7 & 21.7 \\
\hline Friuli Venezia Giulia & 7.9 & 22.0 & 10.4 & 28.1 & 9.2 & 25.1 \\
\hline Emilia-Romagna & 8.1 & 20.8 & 9.3 & 25.9 & 8.7 & 23.4 \\
\hline Toscana & 9.2 & 22.1 & 10.4 & 27.2 & 9.8 & 24.8 \\
\hline Umbria & 8.0 & 22.0 & 8.4 & 26.9 & 8.2 & 24.6 \\
\hline Marche & 7.4 & 21.1 & 8.8 & 26.2 & 8.1 & 23.7 \\
\hline Lazio & 6.3 & 18.3 & 7.6 & 22.9 & 7.0 & 20.7 \\
\hline Abruzzo & 7.7 & 20.2 & 8.8 & 24.9 & 8.3 & 22.6 \\
\hline Molise & 7.7 & 20.7 & 8.8 & 25.9 & 8.2 & 23.4 \\
\hline Campania & 5.8 & 15.6 & 7.2 & 19.4 & 6.5 & 17.6 \\
\hline Puglia & 6.8 & 18.4 & 7.4 & 22.4 & 7.1 & 20.5 \\
\hline Basilicata & 6.2 & 19.3 & 7.0 & 23.9 & 6.6 & 21.6 \\
\hline Calabria & 6.1 & 18.4 & 7.4 & 22.0 & 6.8 & 20.2 \\
\hline Sicilia & 7.5 & 17.8 & 8.4 & 21.9 & 8.0 & 19.9 \\
\hline Sardegna & 7.5 & 19.2 & 8.1 & 23.8 & 7.8 & 21.6 \\
\hline Italy & 7.6 & 19.2 & 8.8 & 24.1 & 8.2 & 21.7 \\
\hline
\end{tabular}

Source: Istat

Moreover, the ageing geography (Chart 2) identifies Liguria (28.0\%) as the region with the highest ageing level for both sexes, while the region with the lowest ageing index is Campania (17.6\%). 
The ageing indeces of the female population, which appear both for all regions and for the whole studied period under study, are remarkable because they are always higher than those of the male population.

The Chart 3 data, concerning the ageing velocity, show that this was $15.6 \%$ for the total population (MF) of our country. That value shows a yearly average increase of 15.6 of people over-65 per 1,000 units.

Note that Basilicata in 1951 had the lowest ageing index (6.6\%). Yet 2015 it is the region with the highest ageing velocity (19.0\%o). This differs from Piemonte which, in the 1951 census, showed the highest population ageing index (11.4\%) while in the time period under study it showed an increased slowdown. These results confirm the hypothesis according to which the traditional demographic divarication between the North and South of Italy might be mainly caused by the dissimilarity in the social and economic models. It appears that a solid welfare system allows for a better territorial development from a health point of view as well.

We should to note also the results of the data concerning the yearly average variation rates of the ageing index derived for the $F$ group: these values are essentially higher than those of the $M$ group. That serves as a further confirmation that the female group contributed to the ageing level increase of the whole Italian population.

Chart 3 - Population ageing velocity of Italian regions

\begin{tabular}{|c|c|c|c|}
\hline Regions & M & F & MF \\
\hline Piemonte & 11.6 & 12.7 & 12.2 \\
Valle d'Aosta & 13.2 & 15.4 & 14.4 \\
Liguria & 14.3 & 16.2 & 15.5 \\
Lombardia & 14.9 & 16.4 & 15.9 \\
Trentino A.A. & 13.6 & 14.6 & 14.1 \\
Veneto & 15.9 & 17.1 & 16.5 \\
Friuli Venezia Giulia & 16.3 & 15.8 & 16.0 \\
Emilia-Romagna & 15.1 & 16.4 & 15.8 \\
Toscana & 14.0 & 15.4 & 14.8 \\
Umbria & 16.2 & 18.6 & 17.5 \\
Marche & 16.7 & 17.4 & 17.2 \\
Lazio & 17.0 & 17.6 & 17.3 \\
Abruzzo & 15.4 & 17.2 & 16.0 \\
Molise & 15.8 & 15.8 & 16.7 \\
Campania & 15.8 & 17.7 & 15.9 \\
Puglia & 15.9 & 19.6 & 16.9 \\
Basilicata & 18.1 & 17.4 & 19.0 \\
Calabria & 17.6 & 15.3 & 17.4 \\
Sicilia & 13.8 & 17.2 & 14.5 \\
Sardegna & 15.0 & 16.1 & 16.2 \\
Italy & 14.8 & 15.6 \\
\hline
\end{tabular}

Source: Authors' elaborations based on Istat data 


\section{Future "estimate" of the ageing rate}

Having determined that in Italian population, in the period between the 1951 census and $1^{\text {st }}$ January 2015, the population ageing reached critical levels, it will be of interest to estimate how this phenomenon might evolve in the future.

As we can analyse the historical series of the Italian ageing indeces of the years between the 1951 census and that of 2011 (as listed in Chart 4 and graphically represented in Picture 1) we are able to produce an extrapolation for the years to come from 2021 to 2041.

Chart 4 - Ageing indexes in Italy. 1951-2011

\begin{tabular}{|c|c|}
\hline Date & Index value \\
\hline 1951 & 8.2 \\
1961 & 9.5 \\
1971 & 11.3 \\
1981 & 13.2 \\
1991 & 15.3 \\
2001 & 18.7 \\
2011 & 20.9 \\
\hline
\end{tabular}

Source: Istat

It should be emphasised that the data of Chart 4 show how our population, until the 1961 census, could be still considered "young" as the ageing index was 9.5\%. Over the years the same index increased until it reached about $21 \%$ in the 2011 census.

Diagram 1

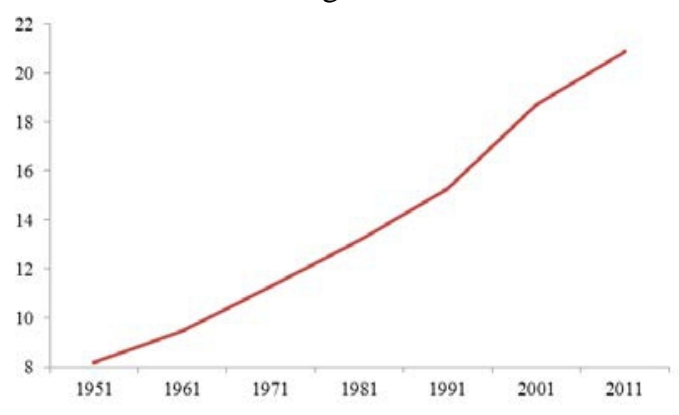

To produce an extrapolation for the future years, we need to choose the most suitable function to represent the time evolution of the ageing index.

From the graphic representation we can intuitively infer that the curve of the ageing indexes can be expressed analytically by this kind of function:

$$
y=\alpha \cdot \beta^{x}
$$


where $y$ is the ageing index of the year $x$, while $\alpha$ and $\beta$ are two constants. To calculate the parameters $\alpha$ and $\beta$ we need to turn $y=\alpha \cdot \beta^{x}$ into a linear function through natural logarithms.

$\ln y=\ln \alpha+x \cdot \ln \beta$

If we linearize, we get

from which if we set

$\ln y=T \quad \ln \alpha=A \quad \ln \beta=B$

we can write

$T=A+B x$

To calculate the values of $A$ and $B$ we can use the least squares method. After setting $x=0,1, \ldots 6$ next to 1951, 1961... 2011 respectively, and admitting they are equidistant, we get the required interpolating function

$$
y^{*}=8,2 \cdot 1,17^{x}
$$

If we replace $x=0,1, \ldots .6$ in it, we can get the theoretical ageing indexes in the time interval 1951-2011 compared with both the empirical values in Chart 5 and graphically in Diagram 2.

Chart 5 - Empirical and theoretical ageing indexes. 1951-2011

\begin{tabular}{|c|c|c|}
\hline Dates & Empirical & Theoretical \\
\hline 1951 & 8.2 & 8.2 \\
1961 & 9.5 & 9.6 \\
1971 & 11.3 & 11.2 \\
1981 & 13.2 & 13.1 \\
1991 & 15.3 & 15.4 \\
2001 & 18.7 & 18.0 \\
2011 & 20.9 & 21.0 \\
\hline
\end{tabular}

Source: Authors' elaborations based on Istat data

Diagram 2

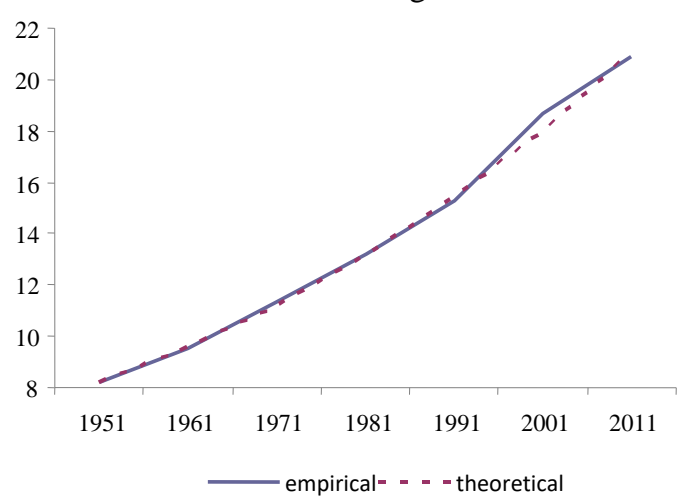

The interpolating function shows that the ageing index in our country - starting from 8.2 over-60 per 100 inhabitants in 1951 - tends to increase with a geometric progression equal to 1.17 . 
Moreover, always considering the interpolating function, if we derive as to $x$ and divide by $y$ we get the relative instantaneous rate of increase of $y$, that is

$$
\frac{y^{\prime}}{y}=\ln 1.17=0.15700
$$

i.e. a relative instantaneous rate of increase of about $16 \%$.

Note also that the interpolating function really fits to the empirical curve of the ageing indexes (Diagram 2) because the deviation index we calculated is equal to $1.24 \%$. Therefore, we can state we have a very good adaptation, as it is lower than $10 \%$.

Now, thanks to suitable substitutions, we can derive the future theoretical ageing indexes for 2021 (24.6\%), 2031 (28.8\%) and 2041 (33.7\%) respectively. These values clearly show a proportional increase of 61\% from 2011 to 2041. (see Chart 6)

Chart 6 - Future extrapolation of the ageing indexes

\begin{tabular}{|c|c|}
\hline Date & Index value \\
\hline 1951 & 8.2 \\
1961 & 9.6 \\
1971 & 11.2 \\
1981 & 13.1 \\
1991 & 15.4 \\
2001 & 18.0 \\
2011 & 21.0 \\
2021 & 24.6 \\
2031 & 28.8 \\
2041 & 33.7 \\
\hline
\end{tabular}

Source: Authors’ elaborations based on Istat data

\section{Consequences of the ageing rate: structural changes}

The increasing trend of the ageing rate is explained by the changes occurring in the population structure per sex and per age.

The structure per sex and age of the Italian population on $1^{\text {st }}$ January 2015 and therefore their ageing level depended on the following factors: the structure per sex and age of the 1951 census, the evolution of the fertility and death rates in relation to age from 1951 to $1^{\text {st }}$ January 2015 and population migration that occurred in the same studied period.

If we do not take the migratory phenomenon into account, as it is physiologically unstable, we can state that the increase in the ageing process increase of the Italian population is caused by trends in the fertility and death rates over the period studied.

In this essay, however, we will only deal with the changes occurred in the structure per age and sex caused by the incidence of the fertility and death rates, thus deferring the evolution path of the natural components mentioned above to further in-depth analyses. 
Conventionally, the structure per age of a population is divided into three major groups: the $0-14$ group relating to the growth and education period, the 15-64 group concerning the working age and the 65+ one (being the retirement period). In Chart 7 one can see the percentage distribution of the population belonging to the these three major age groups as far as the censuses conducted between 1951 and 2011 are concerned as well as the population estimate made by Istat on $1^{\text {st }}$ January 2015.

On analysis of the chart, one can observe how, over the years, the ratio of young people tends to decrease in view of the fluctuating percentage of the central ages population which does not show any remarkable variation either in time nor space. Conversely, the elderly population shows increasing growths.

This kind of situation is due to the combined action of the fertility rate fall and the survival rate. We can infer this also from the above mentioned ageing indeces which always increased from 1951 to $1^{\text {st }}$ January 2015. In detail, as far as the last observed date is concerned, the value is equal to $21.7 \%$. This means that there are about 22 over-60s per 1000 units belonging to the total population. Therefore, we realize that in 63 years of Italian demographic history the ageing index has increased by $165 \%$, thus creating a "remarkable ageing" of the population.

Chart 7 - Population percentage distribution per major groups. 1951 - 01.01.2015

\begin{tabular}{|c|c|c|c|c|}
\hline \multirow{2}{*}{ Years } & \multicolumn{3}{|c|}{ Age groups } & \multirow{2}{*}{ Total } \\
\cline { 2 - 4 } & $0-14$ & $15-64$ & $65+$ & 100.0 \\
1951 & 26.1 & 65.7 & 8.2 & 100.0 \\
1971 & 24.5 & 66.0 & 9.5 & 100.0 \\
1981 & 24.4 & 64.3 & 11.3 & 100.0 \\
1991 & 21.4 & 65.4 & 13.2 & 100.0 \\
2001 & 15.9 & 68.8 & 15.3 & 100.0 \\
2011 & 14.2 & 67.1 & 18.7 & 100.0 \\
01.01 .2015 & 14.0 & 65.1 & 20.9 & 100.0 \\
\hline
\end{tabular}

Source: Authors' elaborations based on Istat data

A noteworthy element (see Diagram 3) is the intersection point between the curves of the very young (0-14 age group) and the elderly people (65+ age group): it symbolizes the equality reached in 1991 by the very young age-group and the over-sixties one. 
Diagram 3

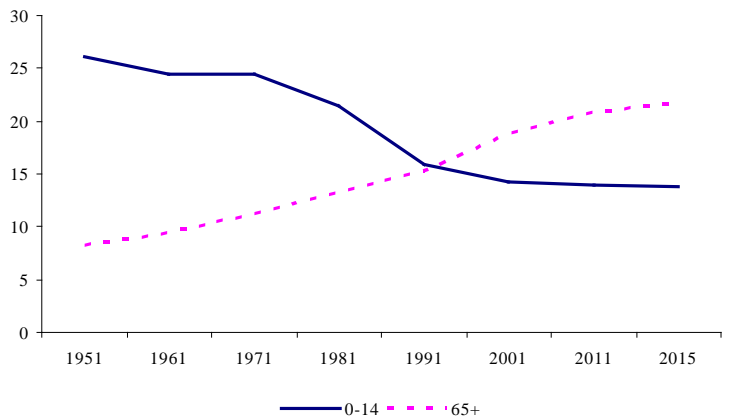

An analysis of the differences between sexes, in the same major groups and in the same studied period (Chart 8), reveals an imbalance. It is readily apparent that in the 0-14 group there is a preponderance of the male sex compared with the female one, the 15-64 group is fundamentally balanced, while the situation changes in the 65+ group where there is a prevalence of the female sex compared with the male one.

Chart 8-M and F population percentage distribution per major groups. 1951-01.01.2015

\begin{tabular}{|c|c|c|c|c|c|c|c|}
\hline \multirow{2}{*}{ Years } & \multicolumn{6}{|c|}{ Age groups } & \multirow{2}{*}{ Total } \\
\cline { 2 - 7 } & \multicolumn{2}{|c|}{$0-14$} & \multicolumn{2}{|c|}{$15-64$} & \multicolumn{2}{|c|}{$65+$} & \\
\cline { 2 - 6 } & $\mathrm{M}$ & $\mathrm{F}$ & $\mathrm{M}$ & $\mathrm{F}$ & $\mathrm{M}$ & $\mathrm{F}$ & \\
\hline 1951 & 13.3 & 12.8 & 31.9 & 33.8 & 3.7 & 4.5 & 100.0 \\
1961 & 12.5 & 12.0 & 32.4 & 33.6 & 4.0 & 5.5 & 100.0 \\
1971 & 12.5 & 11.9 & 31.7 & 32.6 & 4.7 & 6.6 & 100.0 \\
1981 & 11.0 & 10.4 & 32.2 & 33.2 & 5.4 & 7.8 & 100.0 \\
1991 & 8.1 & 7.8 & 34.2 & 34.6 & 6.2 & 9.1 & 100.0 \\
2001 & 7.3 & 6.9 & 33.4 & 33.7 & 7.7 & 11.0 & 100.0 \\
2011 & 7.2 & 6.8 & 32.3 & 32.8 & 8.9 & 12.0 & 100.0 \\
1.1 .2015 & 7.1 & 6.7 & 32.1 & 32.4 & 9.3 & 12.4 & 100.0 \\
\hline
\end{tabular}

Source: Authors' elaborations based on Istat data

This raises the question as to what caused this imbalance between sexes visible in the two extreme major groups? In order to understand this one needs to compare the Italian population structures per sex and age after the 1951 census and on $1^{\text {st }}$ January 2015 first and then calculate the masculinity ratio $(M / F \cdot 100)$ at different ages. (Chart 9 - values expressed by thousands).

The masculinity ratio at birth is equal to 105-106 male births every 100 female births: a constant ratio in time and space (see Chart 9). 
Chart 9 - Resident population, per age and sex groups, after the 1951 census and on 01.01 .2015

\begin{tabular}{|c|c|c|c|c|c|c|}
\hline \multirow{2}{*}{ Age groups } & \multicolumn{2}{|c|}{1951} & \multirow{2}{*}{ Masculinity ratio } & \multicolumn{2}{|c|}{1.1 .2015} & \multirow{2}{*}{} \\
\cline { 2 - 3 } & $\mathrm{M}$ & $\mathrm{F}$ & & $\mathrm{M}$ & $\mathrm{F}$ & Masculinity ratio \\
\hline $0-4$ & $2,218.7$ & $2,113.4$ & 105.0 & $1,363.9$ & $1,288.8$ & 105.8 \\
$5-9$ & $1,981.1$ & $1,892.8$ & 104.7 & $1,475.5$ & $1,390.6$ & 106.1 \\
$10-14$ & $2,141.4$ & $2,074.4$ & 103.2 & $1,474.1$ & $1,390.0$ & 106.1 \\
$15-19$ & $2,036.8$ & $2,003.6$ & 101.7 & $1,479.7$ & $1,384.2$ & 106.9 \\
$20-24$ & $2,062.5$ & $2,038.6$ & 101.2 & $1,581.4$ & $1,501.2$ & 105.3 \\
$25-29$ & $1,959.9$ & $2,023.8$ & 96.8 & $1,659.0$ & $1,623.4$ & 102.2 \\
$30-34$ & $1,381.7$ & $1,476.7$ & 93.6 & $1,814.8$ & $1,797.0$ & 101.0 \\
$35-39$ & $1,675.2$ & $1,757.4$ & 95.3 & $2,128.5$ & $2,125.3$ & 100.2 \\
$40-44$ & $1,664.6$ & $1,714.1$ & 97.1 & $2,406.0$ & $2,425.7$ & 99.2 \\
$45-49$ & $1,409.1$ & $1,476.8$ & 95.4 & $2,462.8$ & $2,509.0$ & 98.2 \\
$50-54$ & $1,182.6$ & $1,327.3$ & 89.1 & $2,279.5$ & $2,366.3$ & 96.3 \\
$55-59$ & 950.2 & $1,179.2$ & 80.6 & $1,950.4$ & $2,068.6$ & 94.3 \\
$60-64$ & 836.9 & $1,041.6$ & 80.3 & $1,748.7$ & $1,881.6$ & 92.9 \\
$65-69$ & 688.9 & 843.5 & 81.7 & $1,699.0$ & $1,862.4$ & 91.2 \\
$70-74$ & 515.5 & 605.3 & 85.2 & $1,368.2$ & $1,594.1$ & 85.8 \\
$75-79$ & 333.7 & 397.9 & 83.9 & $1,194.4$ & $1,523.5$ & 78.4 \\
$80-84$ & 154.4 & 195.7 & 78.9 & 814.4 & $1,232.6$ & 66.1 \\
$85-89$ & 54.8 & 76.9 & 71.3 & 427.3 & 836.8 & 51.1 \\
$90+$ & 10.7 & 17.7 & 60.5 & 173.7 & 492.6 & 35.3 \\
Total & $23,258.8$ & $24,256.7$ & 95.9 & $29,501.6$ & $31,294.0$ & 94.3 \\
\hline
\end{tabular}

Source: Authors' elaborations based on Istat data

The surplus of males decreases when age increases either because of the death rate which is higher than the females' one (male extra death rate) or due to migrations since those who migrate usually belong to the male sex and to the central ages. Nevertheless, that surplus might be caused by a combined effect of the two phenomena; that is why, at a certain age group, there is balance between sexes.

In our two populations (Chart 9) the sex balance is reached in the 2024 age group as regards the 1951-census population, while as for the population estimated on $1^{\text {st }}$ January 2015, the sex balance appears in the 3539 age group.

Even if in different periods, how can one interpret the fact that, in the same population, sex balance is reached in two different age groups? In fact in the Italian population of 1951 the male death rate was higher than the female one. Moreover, the male group was subjected to strong migration flows, thus immediately causing a decrease of the number of males; therefore, the masculinity ratio brought about a sex balance towards the lowest groups of the age structure.

It is to remember that over the years our country has passed from a strong emigration pressure to a strong immigration one, both due to people coming back from European and non-European countries and to people 
arriving from developing countries. Besides, as regards the death rate, the gap between sexes has decreased, thus causing a higher presence of males in the population which created a sex balance towards the higher groups of the age structure with a different masculinity ratio.

For this reason one can state that the sex imbalance in the major 0-14 group, since 1951, is basically due to a longer survival of males compared with the female one, as can be inferred from the percentage comparison of the male and female population from 1951 to $1^{\text {st }}$ January 2015 (Chart 8). However, if one calculate the masculinity ratios in the studied period (Chart 10), it is clear that this imbalance becomes higher over the years until it reaches the value of 160.0 .

This means that males now lead the sex difference in the 0-14 group, mainly due to their higher survival but also, perhaps, because of a juvenile male immigration that explains the shift of the masculinity ratio towards the highest groups of the age structure in the population on $1^{\text {st }}$ January 2015 (Chart 9).

Nevertheless, in spite of the fact that the sex balance observed in the age and sex structure shifted towards the highest ages on $1^{\text {st }}$ January 2015 - a symptom of the increased male survival and possibly of a juvenile male immigration, as we have stated above - a higher male death rate, compared with the female one, still persists in our population and can therefore explain the imbalance we observe in the 65+ age group (Charts 8 and 10).

Chart 10 - Masculinity ratios per major groups. 1951-01.01.2015

\begin{tabular}{|c|c|c|c|}
\hline \multirow{2}{*}{ Years } & \multicolumn{3}{|c|}{ Age groups } \\
\cline { 2 - 4 } & $0-14$ & $15-64$ & $65+$ \\
\hline 1951 & 104.3 & 94.5 & 82.3 \\
1961 & 104.6 & 96.5 & 73.2 \\
1971 & 105.1 & 97.1 & 71.8 \\
1991 & 105.1 & 97.3 & 69.5 \\
2001 & 105.4 & 98.7 & 68.3 \\
2011 & 105.5 & 99.1 & 70.0 \\
01.01 .2015 & 106.0 & 98.4 & 73.7 \\
\hline
\end{tabular}

Source: Authors' elaborations based on Istat data

As illustrated graphically shown, through the 1951 and 01.01 .2015 age pyramids, the changes occurred in the respective age structures in a 63year period (Diagrams 4 and 5).

The common opinion in literature is that the above mentioned graphical representation shows us the existing interconnection between the structure of a population and the history of the formative generations thus creating the shape as well.

There is a clear shape change of the two age pyramids. Actually, Italy passed from a pyramid with a classical outline (Diagram 4) - whose base is 
wider due to a high birth rate and whose increasing narrowing up to the oldest ages is caused by the combined effect of a linear death rate among the emigration groups - to a pyramid with a contracting outline (Diagram 5) characterized by a narrower base compared with the central sector which then widens because of a strong flow of immigrants and in the final part slowly narrows.

In addition to the clear increasing "feminization" of the population structure due to a higher female survival, in the same way one can note the pyramid's ageing process starting from below caused by the low fertility rate of the Italian population.

Diagram 4
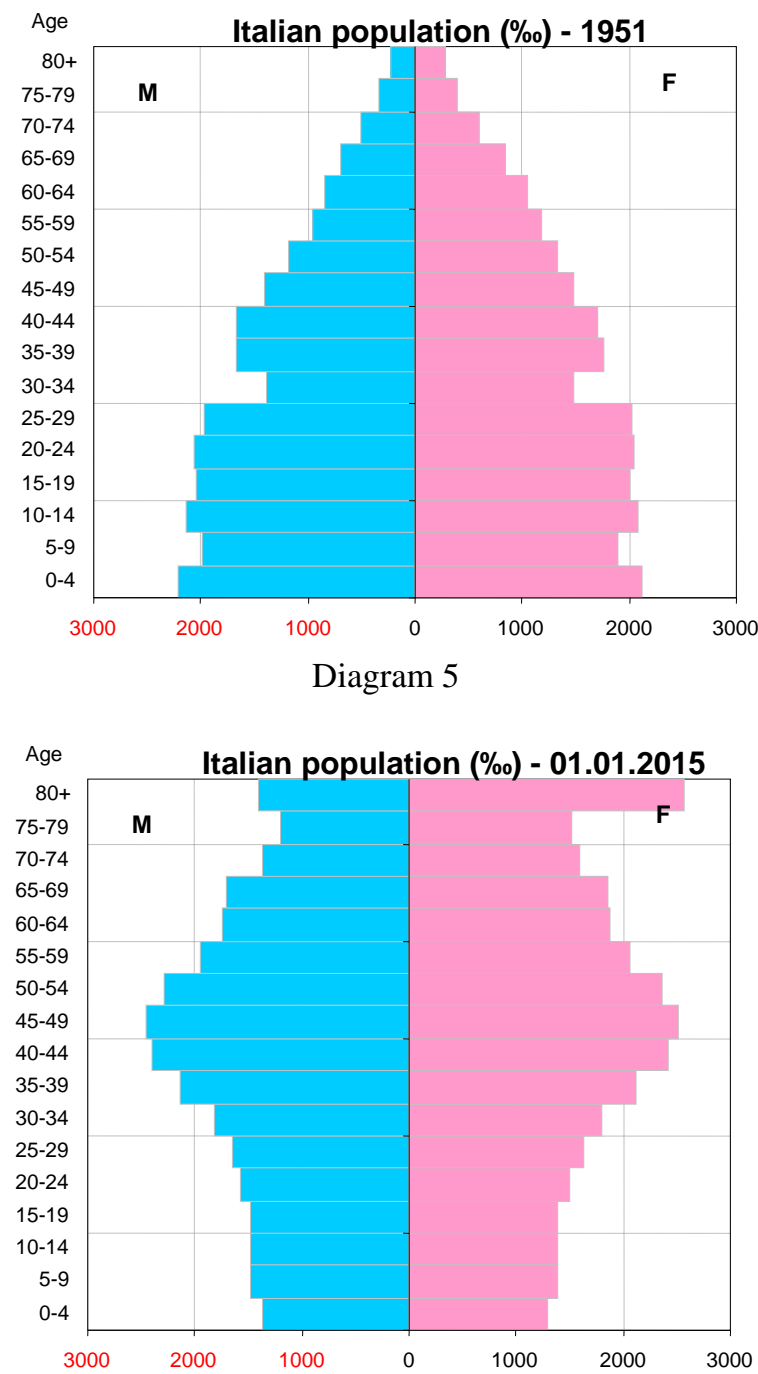

In this essay the authors have shared a well-known demographic concept concerning the grouping of an entire population that is considered 
elderly into the open 65+ group. This has the effect of making the old and the very old people "invisible". The authors believe that they should not "stay hidden" any longer because of both their remarkable number and the importance they have from an economic, political and social point of view.

In the past the number of people who were older than 80 and 85 was smaller and therefore their proportional importance in the total population was negligible. Nowadays, however, the numerical importance of very old people has increased; therefore, one should no longer postpone a distinction within the 65+ group that could be divided into three subgroups:

1) the elderly people between 65 and 74 years old;

2) the old people between 75 and 84 years old;

3 ) the very old people who are older than 85 years old.

The percentage distribution of the above mentioned groups out of the total population in the various observed years can be seen in Chart 11, which shows that the population segment belonging to the $85+$ group is increasing compared with the other ones: the percentage increase compared with 1951 is equal to $966.7 \%$.

Starting from this remarkable increase one can hypothesize a "fourth age" due to the gradual growth in importance of the old age sectors which will involve an ageing process starting from the top. This kind of process must simulate careful thought make about the development policies that should be used, thus understanding the real needs in order to face the expected changes.

Chart 11 - Percentage distribution of the elderly groups. 1951-01.01.2015

\begin{tabular}{|c|c|c|c|c|c|c|c|c|c|}
\hline Age & \multicolumn{7}{|c|}{ Years } & $\begin{array}{c}\text { Percentage } \\
\text { increase }\end{array}$ \\
\cline { 2 - 10 } & 1951 & 1961 & 1971 & 1981 & 1991 & 2001 & 2011 & 01.01 .2015 & 91.1 \\
$65-74$ & 5.6 & 6.2 & 7.4 & 8.5 & 8.6 & 10.3 & 10.5 & 10.7 & 239.1 \\
$75-84$ & 2.3 & 2.8 & 3.2 & 3.9 & 5.4 & 6.2 & 7.5 & 7.8 & 966.7 \\
$85+$ & 0.3 & 0.5 & 0.7 & 0.8 & 1.3 & 2.2 & 2.8 & 3.2 & 9 \\
\hline
\end{tabular}

Source: Authors' elaborations based on Istat data

\section{Final considerations}

The conclusions reached in this essay lead one to consider the population ageing as a multidimensional phenomenon pointing to different problems to cope with. Nevertheless, one must not forget the basically positive aspect of a population that shows a better state of health.

As is well known the progressive rise of average lifespan created the shift to a demographic system characterized by the degenerative diseases tied to senescence. However, the fundamental matters already discussed in the Second World Assembly on Ageing ${ }^{1}$, concerning the challenges issued by the rapid ageing of the population, stressed the need to integrate elderly

\footnotetext{
${ }^{1}$ Madrid, Spain, 8-12 April 2002
} 
people with society, give them health and welfare and guarantee a favourable environment for their support and initiative ability.

Ageing in the twenty-first century: an aim or a challenge? One should mainly hope for a momentous turning point in the social policies which will be able to change the behaviours of individuals and families. As a matter of fact, a lot has lately been said lately about the repercussions that ageing will have in the labour market, on the social integration of old people, on the sustainability of the welfare and health systems. For this reason Europe started spreading the culture of the "active ageing”, considered as a group of measures to improve life and the participation of the older generations thanks to tools like the continuous training and the involvement in socialization and voluntary work initiatives.

However, in order to prevent people from considering the elderly only as recipients of social services but rather as active participants in the development process with full rights, what is mainly required is a change in behaviours, attitudes and habits that do not belong to the present reality.

In Italian society, the welfare burden usually rests on the family, when there is one. Several studies have shown how family ${ }^{2}$ is the subsidiary element against the Government and therefore the social and health services. Unfortunately, it is a welfare burden that families will be able to bear less and less, mainly due to the evolution of family units (fewer children, fewer weddings, rise of unipersonal families) which is progressively modifying the Italian social structure. In our country, families have traditionally played a role of social security cushion which marched side by side with the main tools of public policy. However, the structural changes of the family solidarity nets and the increasing difficulties of the labour market have weakened their subsidiary function. As far as demography is concerned, the various perspective interpretations of the ageing phenomenon highlighted that this could become a real social emergency with consequences for the development and sustainability perspectives of the national system. Unfortunately, all that will influence not only the economic aspects but also the family contexts, supported by a welfare system that is one of the least efficacious in Europe.

Actually, the so-called Reher model of the strong family of Middle and South Europe, characterized by a particular joint of mutual obligations

\footnotetext{
${ }^{2}$ For example, according to a Censis survey carried out in 2004 (CENSIS, Analisi comparativa dei principali servizi per gli anziani non autosufficienti, 2005, http://www.ministerosalute.it/_resources/static/news/734/indagine_anziani_fragili. pdf, 29 marzo 2010), 75.1\% of the Italian old people, in case of diseases or invalidity, are helped by their children, $41.6 \%$ by their spouse/cohabitant, $20.6 \%$ by other relatives and $4.1 \%$ by their neighbours. Only $1 \%$ of the interviewees, in case of need, are helped by the territorial health services and $0.8 \%$ by social services.
} 
between generations, is now in decline precisely because of the well-known fragility of the support between generations.

For this reason, in the very near future it is important to monitor the increase of the aged population in absolute and relative terms. There is also an obligation to carefully consider the health conditions of that population together with the daily life exigencies, thus fixing the real effects of this phenomenon development.

\section{References:}

1. CAGIANO de AZEVEDO R., CAPACCI G., (2004), Invecchiamento e svecchiamento della popolazione europea, Aracne editrice, Roma.

2. CASELLI G., EGIDI V., (2011), Una vita più lunga e più sana, in GOLINI A., ROSINA A. (a cura di), Il secolo degli anziani. Come cambierà l’Italia, Il Mulino, Bologna.

3. CENSIS: (2004) (http://www.ministerosalute.it/ resources/static/news/734/indagine_anziani_fragili.

pdf, 29 marzo 2010), 75.1\% of the Italian old people, in case of diseases or invalidity, are helped by their children, $41.6 \%$ by their spouse/cohabitant, $20.6 \%$ by other relatives and $4.1 \%$ by their neighbours. Only $1 \%$ of the interviewees, in case of need, are helped by the territorial health services and $0.8 \%$ by social services.

4. EUROSTAT (2012), Demographic outlook. National reports on the demographic developments in 2010, Population and social conditions, Methodologies \& Working papers.

5. EUROSTAT (2014), EUROPOP-2013. Population projections at national level, in http://epp.eurostat.ec.europa.eu/portal/page/portal/statistics/search_da tabase.

6. ISTAT (2011), Il futuro demografico del Paese. Previsioni regionali della popolazione residente al 2065, Statistiche Report, Roma.

7. ISTAT (2015), Annuario statistico.

8. LIVI BACCI M., Introduzione alla Demografia, ultima edizione, Loescher Ed.

9. REHER D.S., (1998), Family ties in western Europe: persistent contrast, Population and Development Review.

10. SACCO G.- SACCO P., 2016 - The Valency of the natural and social components as determinants of a population's future development, ESJ (European Scientific Journal) Vol. 12, N.8 , March Edition 2016, (ESI PUBLISHER), pagg. 284-297, ISNN 1857-7431.

11. SARACENO C.,(2003), Mutamenti della famiglia e politiche sociali in Italia, Il Mulino, Bologna. 